\section{The research} experience: Reflections

\section{of a novice}

\section{researcher}

\section{By Maureen E. Dorion and Heather B. Porter}

\section{Abstract}

The oncology nurses at the Windsor Regional Cancer Centre $(W R C C)$, like other health professionals, realize that professional proficiency can be improved through systematic strategies designed to enhance and streamline patient care. For this reason, all nurses in the systemic therapy department of the WRCC agreed to take part in a research study called "Effectiveness and Efficiency of Nurse-Given Cancer Patient Education" (Porter, 1998). Their opinions, accomplishments and feelings about this research experience are recorded under selected headings of the research process.

\section{Introduction}

The oncology nurses at the Windsor Regional Cancer Centre, like other health professionals, realized that professional proficiency can be improved through systematic strategies designed to enhance and streamline patient care. For this reason, all nurses in the systemic therapy department of the WRCC agreed to take part in a research study called "Effectiveness and Efficiency of Nurse-Given Cancer Patient Education" (Porter, 1998). For two years, these WRCC oncology nurses monitored their practice, timed the nursing activities

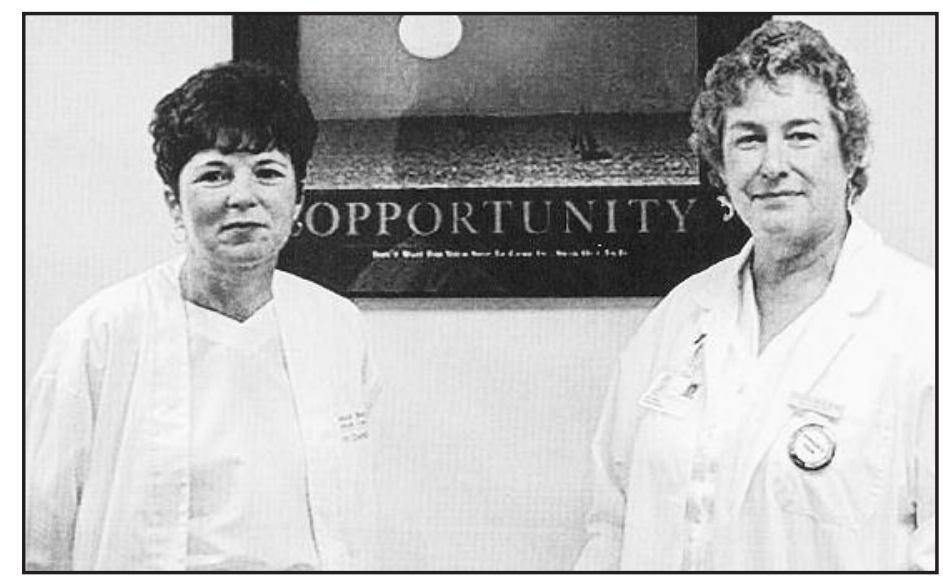

Maureen Dorion and Heather Porter. under scrutiny in this project with stop watches, remembered to record their observations and evaluations each day and assisted the researchers consistently in the activities of participant recruitment and retention.

Their opinions, accomplishments and feelings are taken from the diary of co-author M. Dorion, a WRCC oncology nurse and the research associate for the study. They are recorded here under selected headings of the research process.

\section{Research associate role}

"I realize that two qualities that benefit a research associate are good organizational skills and the ability to be persuasive if necessary. Since I felt I possess those skills, I felt more confident assuming this role. There are other skills that develop too. Being an effective communicator is very important. Some of the skills I developed are communication skills and computer competence."

"Even though I had no experience working in research except for my exposure to the clinical trials going on in our centre, I felt it was important for someone from our own staff to take the position. Being able to recognize each nurse's handwriting, knowing them personally and having the opportunity to speak to them daily really enhanced data collection."

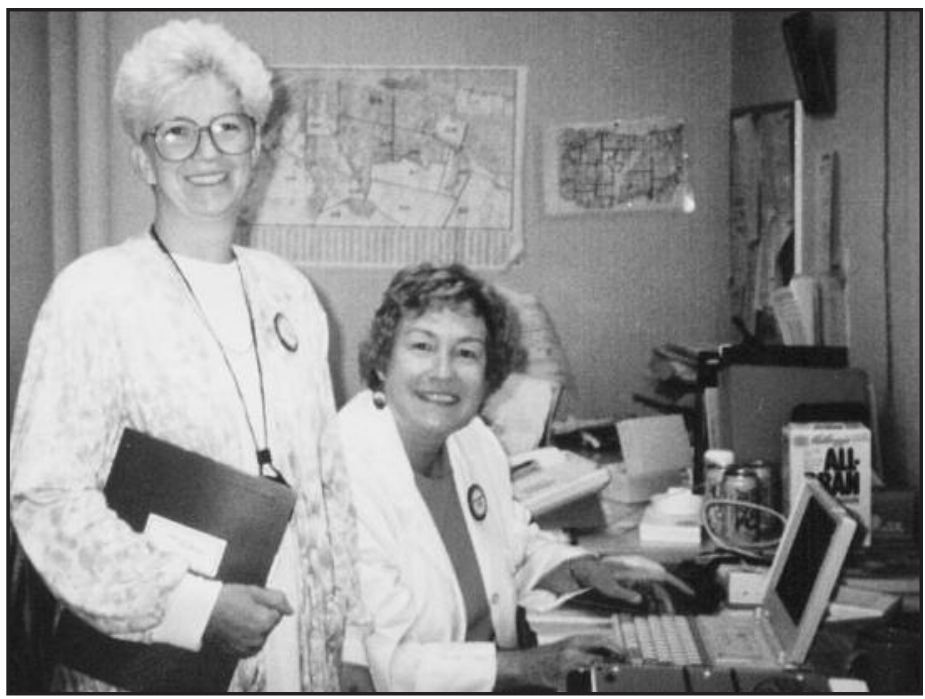

Collecting data.

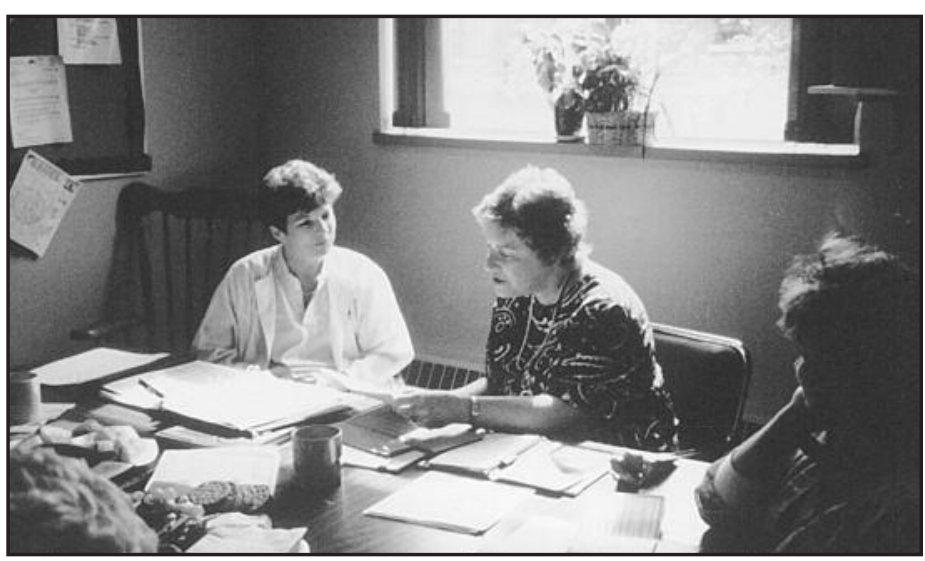

A research discussion.

Maureen E. Dorion, RN, CON $(C)$, is an oncology nurse in the systemic therapy department at Windsor Regional Cancer Centre in Windsor Ontario. Heather B. Porter, RN, PhD, is adjunct assistant professor, School of Nursing,

University of Western Ontario, London, Ontario, and a health services consultant in Kitchener, Ontario. 
"I think it's important that people take the initiative to get involved with research even if they don't have the experience. It's a great opportunity to learn."

\section{Methods}

\section{Procedure}

"The nursing staff had a meeting to talk about the study. We talked about how nursing research validates our professional practice, adds to our knowledge base and tests new methods of care. We confirmed that this data collection is an additional burden to our workload so the challenge was to stimulate staff, keep them interested and make data collection as easy as possible. One of our nurses with a great sense of humour offered to help host parties from time to time to help keep the staff motivated."

"A teaching session was planned with the nurses in the department when we discussed the goals of the study. After role playing the accrual and data collection process and a general discussion, all the nurses signed the consent and agreed to wear a button which identified us as a WRCC research team."

"We decided to give each patient, at the end of three months, a key chain that depicts the flame of hope, or an angel pin. Each of these gifts has a little card that says 'thank you for helping us improve cancer care'. Today I received a thank you card from a patient for her gift and for being able to participate in the study."

"It was helpful in many ways to have the RA as part of the staff and other nurses were very good about relieving me when I had a patient to put on the study on a day that I was not assigned RA duties. My presence each day in the clinic was a constant reminder to staff and patients about the study. For example, a subject with a good sense of humour said that every time he saw me he thought of his log book and it reminded him to keep it up to date."

\section{Difficult times}

July 26, 1995: "I can see at times that it is very time-consuming and draining for the staff to have to time their teaching activities and telephone messages and they get frustrated with the stop watches because they are quite sensitive and difficult to set. But I think that the conscientiousness of our staff is very impressive."

December 6, 1995: "Today is the first day I have actually wondered why I took this job on. As RA I feel responsible when I find out that things are not being done in the same way by everyone. But these are

Table One: Nurse-given patient education programs

\begin{tabular}{|l|l|}
\hline Program One & Program Two \\
\hline $\begin{array}{l}\text { Disease site information } \\
\text { (developed by Windsor } \\
\text { Regional Cancer Centre) }\end{array}$ & $\begin{array}{l}\text { "Managing the Effects of } \\
\text { Chemotherapy and Radiation } \\
\text { Therapy" } \\
\text { Marylin J. Dodd, 1996 }\end{array}$ \\
\hline $\begin{array}{l}\text { "Talking about Chemotherapy" } \\
\text { (developed by Ontario Cancer } \\
\text { Treatment and Research }\end{array}$ & $\begin{array}{l}\text { Treatment schedule } \\
\text { Diary } \\
\text { (both tucked in pockets of } \\
\text { the Dodd book) } \\
\text { OR }\end{array}$ \\
$\begin{array}{l}\text { "Understanding Chemotherapy" } \\
\text { (developed by Eli Lilly Canada } \\
\text { with the Canadian Association of } \\
\text { Nurses in Oncology) }\end{array}$ & \\
\hline $\begin{array}{l}\text { Drug information sheets } \\
\text { (developed by WRCC pharmacy) }\end{array}$ & \\
\hline \begin{tabular}{l} 
Treatment schedule \\
\hline
\end{tabular} & \\
\hline
\end{tabular}

all my peers and I find it best to approach the inconsistencies by reinforcing that this study validates the nurses' role in our centre."

May 20, 1997: "At this point, after nearly two years, the staff is getting a little tired of the study and they are ready for it to come to an end. The study is winding down now that we are no longer accruing subjects. Sometimes it's really hard to keep focused on it."

\section{Data collection}

"This is my favourite data collection story: It is crucial that we obtain all data on as many patients as we can so we have enough in the sample to get good results. Because we lose subjects due to death or change of treatment, we need all information on all the remainder. The log book is usually the hardest to retrieve. Today I called a patient to schedule an appointment with her to complete the final questionnaire. She was at her cottage in the country and would not be back to town because she was scheduled for surgery the next week. I asked her if she had access to a fax machine and she said there was one at the bank in a nearby town. I called the bank and made arrangements to send the questionnaire by fax, she picked it up and we did it together over the phone. Then she mailed the log book to me. If you go that extra distance, it really helps with data collection."

"Another story! - When Subject 1 came in for her second treatment she had kept a list of all her side effects but did not feel confident entering them in her log. I assisted her in entering the information. Later, when she came in to do the final questionnaires, she brought in eight pages of notes, a list of all her medications and a summary of how she felt each day!"

\section{The intervention}

Nurse perspective. "There was a great deal of preparation before we could start the experimental arm. Dr. Dodd demonstrated for the staff how to use her teaching book (the Dodd book) with patients. This method consists of highlighting the pages of the book describing the patient's prescribed drug(s) and reviewing possible side effects and signs and symptoms listed for each one. The patient is then shown where in the book to find suggestions for managing those side effects.

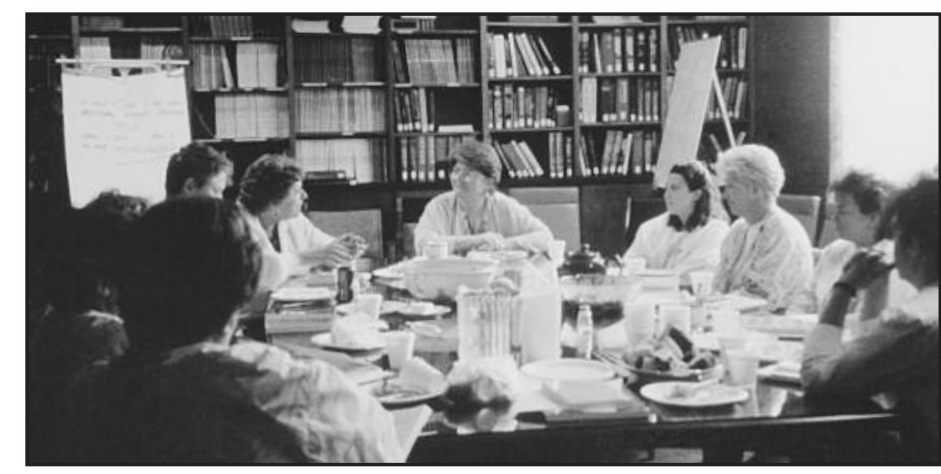

A lunch party with Dr. Dodd (centre).

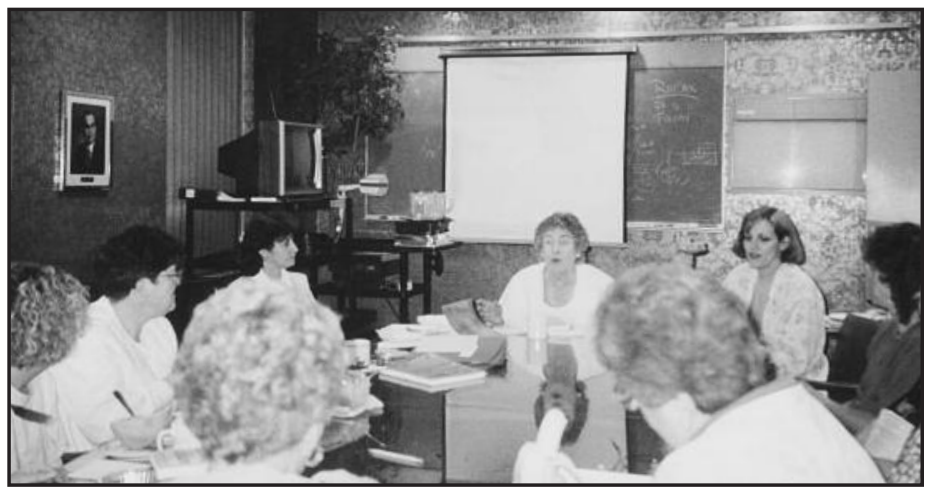

A learning session. 
Their treatment schedule and diary are placed in the pockets of their Dodd book. Finally, patients are encouraged to bring their book with them to each clinic visit as a reminder and guide for ongoing questions and teaching.

Every member of the staff reviewed the book and brought forward suggestions on how to adapt the book to the WRCC. Then the book was revised and all copies adjusted to meet the needs of our practice.

Nursing staff found it very awkward at first to change the method by which they teach patients. Their usual method is to review with each patient a number of pamphlets that cover the specific type of cancer the patient is experiencing, chemotherapy, the cancer drugs the patient has been prescribed and the patient's treatment schedule. Patients are encouraged to call the clinic if they have any questions. Once nurses were accustomed to putting patients on this arm, they liked the Dodd book, especially the size of the 1991 version. Generally they found it quicker and they feel that the patients do have all the information they need, even if it has not all been given to them verbally.

It has occurred to us that the type of patient who has most benefitted from the Dodd book is the one who really wants to be informed, although sometimes that is not obvious at their first visit." Patient perspective. "A patient told me today that the book was not just for her, but for the entire family. I have noticed many of the study patients bring in their books for their appointments. They really seem to enjoy them."

"One of the nurses overheard a conversation between some patients in our treatment room. A patient who was not on the study was mentioning the side effects he was having. Another patient on the study quoted from the Dodd book some ways to manage these side effects. The nurse's comment was that he knew the book better than she did!"

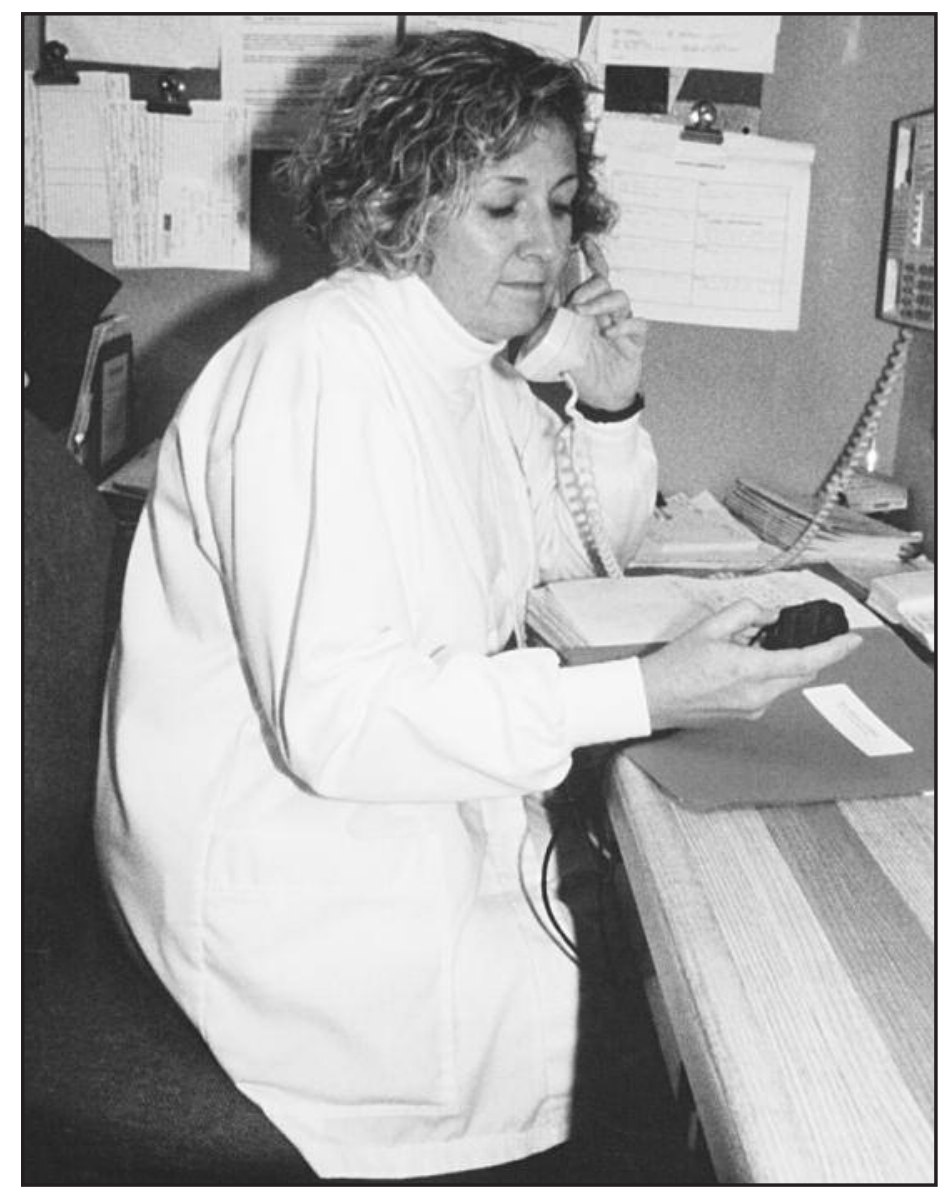

Nurse/patient telephone support.
"A new patient on the experimental arm had a physician husband and scientist son. Both read the Dodd book and found it very helpful. Another patient said she'd heard about the study and wanted to go on it so it would help her feel in control."

"A study patient told me this week that she's read the book from cover to cover and I also noticed one patient who was finished the study two months ago still carries her book wherever she goes. But another patient completing the study was willing to return the book because she said it was very boring."

\section{Instruments}

"A previous patient accompanying one of our experimental subjects said he felt that drug information sheets only about your own drugs were better than the Dodd book because he didn't like the idea that patients had all that information about all drugs and side effects. He felt it would be too frightening."

"A subject who came in for treatment said she no longer wanted to be on the study. She had a young child at home and was feeling overwhelmed. I explained to her that if she felt too overwhelmed to fill in the log book to give it a break. I stressed to her that she should just do the best she could. She agreed to resume being on the study."

"When a patient saw the log book she didn't want to go on the study. She said whatever side effects she had she didn't want to see them in print. However, another subject felt that by being in charge of the log book it gave her control over her diagnosis and treatment."

"As one subject did the final questionnaire, she did not mark off anything for side effects, but I noted that her daughter was not with her, though she had been for the Time 1 questionnaire. Families really help."

\section{Findings}

"Most phone calls were patient-initiated, but a small portion are nurse-initiated. For example, I called a subject to have her bring in the $\log$ book and she talked to me about her nausea."

\section{Future research}

"A former study patient now being treated with radiotherapy could not find her Dodd book and asked for another one in the radiotherapy department. She was quite distressed when they didn't have a copy. She knew there was information in it concerning radiotherapy and she felt it was important to have it so she came back to us for a copy."

\section{Conclusion}

"I think one of the most remarkable things about being involved in this study has been the commitment of the staff and the skills they have developed. We have learned how to make our own slides and to be more comfortable giving talks at meetings or a conference to share the way we take care of our patients. We certainly have become more aware of how we teach and support our patients and how much time it takes."

\section{Acknowledgements}

This study was generously supported by research funding from the Windsor Regional Cancer Centre (WRCC), Windsor, Ontario.

Sincere thanks for their interest and involvement are due to Dr. Ethan Laukkanen, CEO, and the entire staff of the WRCC systemic therapy department. Special thanks to the oncology nurses in that department for their steadfast commitment to this study: R.A. Girard, nurse manager, M. Dorion, research associate, S. Austen, H. Binder, M. Dennis, M. Genna, A. McDowell, C. Reaume, P. Ross, A. Symonds, C. Thoman, N. Pendelly (VON) and M. Schmidt (CCAC).

\section{Reference}

Dodd, M.J. (1996). Managing the side effects of chemotherapy \& radiation therapy: A guide to patients and their families (3rd ed.) San Francisco, CA: UCSF Nursing Press. 